\title{
INFECÇÃO DO TRATO URINÁRIO: ACHADOS LABORATORIAIS DE EXAMES DE URINA EM HOMENS IDOSOS NO PRIMEIRO TRIMESTRE DO ANO DE 2016 NA CIDADE DE PARNAIBA-PI
}

\section{Rafael Cunha da SILVA*, Ana Carolina Santos de ASSIS, Renan da Silva MELO, Vinicius Ribeiro dos SANTOS \& Cláudio Ângelo VENTURA}

Universidade Federal do Piauí. Parnaíba, Piauí, Brasil.

* Autor para correspondência: rafaelcunhadasilva@ hotmail.com

DOI: http://dx.doi.org/10.18571/acbm.137

\section{RESUMO}

As complicações e a gravidade da infecção do trato urinário determinam-se pela vulnerabilidade do paciente e pelas complexas interações entre o hospedeiro e o patógeno. O presente trabalho teve como objetivo mostrar a importância da análise do exame de urina tipo I, em 163 idosos do sexo masculino da cidade de Parnaíba - PI, bem como identificar possíveis achados que predispõem a ocorrência de ITU. Para análise comparativa foram confeccionadas tabelas, distribuindo os resultados em diferentes faixas etárias avaliando os aspectos físicos, químicos e de sedimento. Verificou-se que para a presença de nitrito 3,1\% foram positivos. Para leucócitos e hemácias, quanto à característica incontáveis, foram encontrados 3,1\% e 2,4\% respectivamente, logo, foi necessário dar importância para variáveis com menor frequência, pois entende-se que uma pequena parcela a curto prazo pode representar uma grande quantidade de idosos ao decorrer do ano. É imprescindível ficar atento a prevalência de ITU, ao possível grau de suscetibilidade que pode ser apresentado e que mais estudos sejam realizados na área, tendo assim, um controle mais específico de qual faixa etária é a mais acometida.

Palavras chave: Infecção; Epidemiologia; Urinálise; Saúde Pública.

\begin{abstract}
The severity of the urinary tract infection (UTI) and its resulting complications are determined by the patient's vulnerability and the complex interactions between the host and the pathogen. The aim of the present study was to show the importance of urine analysis - type I, in 163 elderly men from the city of Parnaíba, state of Piauí, as well as to identity possible findings that can predispose the occurrence of UTI. In order to make comparative analysis, the data were, distributed in different groups of age and the physical, chemical and sediment aspects were evaluated. It was observed that $3.1 \%$ of the 163 patients were positive to presence of nitrite. While $3.1 \%$ and $2.4 \%$ were positive to the presence of uncountable erythrocytes and leukocytes respectively. Thus, it was necessary to give importance to less frequent variables, once a small group of affected elderly patients might be related to higher numbers during the year. It is essential to be aware of the prevalence of UTI and the possible degree of susceptibility that can be presented. More studies are necessary, in order to have a more specific control of which age group is the most affected.
\end{abstract}

Key words: Elderly men; Infections; Epidemiology; Urinalysis; Public Healthy.

\section{Introdução}

A infecção do trato urinário (ITU) representa uma afecção frequente tanto em pacientes internados em hospitais, quanto na comunidade. Nos EUA a ITU é responsável por, em média, 8,3 milhões de visitas médicas por ano e está em segundo lugar no índice de infecções mais 
prevalentes, de forma que nos países em desenvolvimento a situação não é diferente (MASSON, 2009). A mesma é caracterizada pela presença de microrganismos patogênicos nas vias urinárias, frequentemente bactérias, que podem acometer tanto as estruturas do trato urinário superior quanto as estruturas do trato urinário inferior. Dessa forma, as ITUs podem ser classificadas em: altas, que envolvem o parênquima renal (pielonefrite) e os ureteres (ureterite) e baixas, abrangendo a bexiga (cistite), uretra (uretrite) e, no caso de homens na próstata (prostatite) e epidídimo (epididimite) (SBU, 2004).

A incidência de ITU varia de acordo com a faixa etária, sendo mais comum no sexo masculino durante o primeiro ano de vida, por conta da maior ocorrência de malformações congênitas (válvula da uretra posterior) e malformações da uretra (hipospádia, epispádia, entre outras). Os problemas da próstata fazem com que a incidência volte a aumentar no sexo masculino

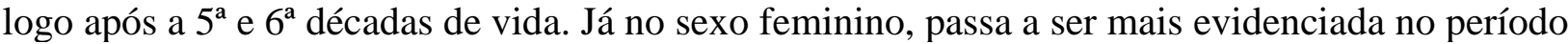
que compreende da idade pré-escolar à fase adulta, onde nesta última, está associada com atividades sexuais, gestação e menopausa (ZAMAN, 1998).

As complicações e a gravidade da ITU determinam-se pela vulnerabilidade do paciente e pelas complexas interações entre o hospedeiro e o patógeno. A sintomatologia clínica varia de acordo com a faixa etária, a localização da infecção, o estado nutricional do paciente e alterações anatômicas e funcionais do trato urinário (SILVA, 2014). A ITU classifica-se como não complicada quando ocorre em pacientes com normalidades anatômicas e funcionais do aparelho genitourinário e é adquirida fora do ambiente hospitalar. As condições nas quais associam-se a ITU complicada incluem as de causa obstrutiva, anátomo funcionais, metabólicas, uso de cateter de demora ou qualquer tipo de instrumentação e procedência infiel (SANTOS, 1999).

Um dos principais exames que auxiliam na orientação terapêutica das infecções do trato urinário é o exame de urina tipo I, composto por exame físico, químico e microscópico do sedimento, a saber que as duas primeiras etapas são de realização mais simples e a última é classificada como relativamente complexa (CARVALHAL, 2006). Algumas alterações como a leucocitúria, hematúria e proteinúria sugerem ITU, mas nem sempre são indicativos de infecção, podendo apresentar-se como sinais inflamatórios ou ainda estar presente em outras doenças (DUARTE, 2008).

Em função da literatura escassa sobre estudos voltados para a saúde do homem idoso, o presente trabalho teve como objetivo mostrar a importância da análise do exame de urina tipo I, em idosos do sexo masculino, durante o primeiro trimestre de 2016 como possível indicação de ITU. Objetivou também, corroborar para um melhor entendimento sobre o assunto pelos profissionais da saúde.

\section{Materiais e Métodos}

A análise desenvolveu-se a partir de dados secundários obtidos no setor de arquivos de um laboratório particular de análises clínicas situado em Parnaíba, cidade litorânea localizada no norte do estado do Piauí a 334km da capital Teresina, com população estimada de 150.201 habitantes (IBGE, 2016). Foram colhidas informações de 163 exames de urina tipo I de pacientes do sexo masculino atendidos durante o primeiro trimestre do ano de 2016, com idade igual ou superior a 60 anos.

Trata-se de uma pesquisa quantitativa, retrospectiva, de observação estruturada não participante, de cunho comparativo e exploratório, onde a análise da frequência relativa dos dados colhidos se deu por meio de tabelas. Os resultados obtidos foram distribuídos em faixas etárias (60 a 70 anos, 71 a 81 anos e idade igual ou superior a 82 anos) e relacionados de acordo com os aspectos físicos, químicos e de sedimento urinário por meio do método de leitura em fita reativa e visualização microscópica em lâmina e lamínula. 
Os aspectos físicos foram analisados de acordo com a coloração (amarelo claro, amarelo citrino e amarelo âmbar), densidade (intervalo dos valores de 1000 a 1030), aspecto (límpido, semiturvo e turvo), depósito (presente ou ausente) e $\mathrm{pH}$ (entre 5,0 e 8,5).

Por meio do exame químico avaliou-se proteínas e glicose (negativas, traços ou positivas), cetonas, bilirrubina, urobilinogênio, hemoglobina e nitrito (positivos ou negativos), enquanto na microscopia do sedimento (sedimentoscopia) subclassificou-se em leucócitos e hemácias (3 a 5, moderados ou incontáveis), muco (raro, frequente ou aumentado), células epiteliais (raras ou frequentes), cilindros (presentes ou ausentes), flora bacteriana (discreta, moderada ou aumentada) e cristais (ausentes ou conforme o tipo encontrado, podendo ser ácido úrico, fosfato triplo, oxalato de cálcio e urato amorfo).

Em seguida, com intuito de evidenciar a relevância das variáveis quanto sua presença ou a quantidade que cada uma poderia se mostrar, realizou-se o cálculo de porcentagens. Após tabulação dos dados obtidos, deu-se a produção e análise de gráficos e tabelas através dos programas Microsoft Office Excel® 2013 e Microsoft Office Word® 2013.

\section{Resultados}

Com os resultados dos diferentes parâmetros obtidos no setor de arquivos de um laboratório particular de análises clínicas, foram traçados perfis etários para facilitar a análise de dados, e dessa forma avaliar a frequência que determinados achados se apresentavam. Dentre os resultados encontrados para coloração verificou-se, como mostra na tabela 1, que as urinas apresentaram coloração amarelo claro $(76,1 \%)$, amarelo citrino $(10,4 \%)$ e amarelo âmbar $(13,5 \%)$.

O grau de translucidez da urina é avaliado pelo aspecto e retrata a quantidade de sedimentos suspensos. Foram achados $12,8 \%$ para o aspecto límpido, $79,1 \%$ para semi-turvo e $7,9 \%$ para turvo. Em relação a depósitos observou-se que 7,3\% estavam presentes e 92,6\% ausentes (tabela 1). A turbidez não é verificada em condições normais, de forma que tal mudança será constatada mediante também ocorra modificação nos depósitos e, por consequente, na microscopia. Desse modo existe uma relação equivalente entre o aspecto da urina e o depósito, além da série de estruturas visualizadas na microscopia. Na presente pesquisa foi encontrado em sua grande maioria um pH levemente ácido 6,0 (53,99\%) e 6,5 (41,7\%). 
Tabela 1: Distribuição das análises de urina quanto os parâmetros físicos.

\begin{tabular}{|c|c|c|c|c|}
\hline \multirow[b]{2}{*}{ PARÂMETROS FÍSICOS } & \multicolumn{3}{|c|}{ FAIXA ETÁRIA (Anos) } & \multirow[b]{2}{*}{$\%(\mathbf{N})$} \\
\hline & $60-70$ & $71-81$ & $\geq 82$ & \\
\hline \multicolumn{5}{|l|}{ Coloração } \\
\hline - Amarelo Claro & $76,47 \%(78)$ & $74,47 \%(35)$ & $78,57 \%(11)$ & $76,07 \%(124)$ \\
\hline - Amarelo Citrino & $9,80 \%(10)$ & $12,76 \%(06)$ & $7,14 \%(01)$ & $10,42 \%(17)$ \\
\hline - Amarelo Âmbar & $13,72 \%(14)$ & $12,76 \%(06)$ & $14,28 \%(02)$ & $13,50 \%(22)$ \\
\hline \multicolumn{5}{|l|}{ Densidade } \\
\hline - $\quad 1.005$ & $1,96 \%(02)$ & $93,62 \%(44)$ & $85,71 \%(12)$ & $35,59 \%(58)$ \\
\hline - $\quad 1.010$ & $1,96 \%(02)$ & $4,25 \%(02)$ & $7,14 \%(01)$ & $3,06 \%(05)$ \\
\hline - $\quad 1.015$ & $95,09 \%(97)$ & $2,12 \%(01)$ & $7,14 \%(01)$ & $60,73 \%(99)$ \\
\hline - 1.020 & $0,98 \%(01)$ & $0 \%(00)$ & $0 \%(00)$ & $0,61 \%(01)$ \\
\hline \multicolumn{5}{|l|}{ Aspecto } \\
\hline - Límpido & $10,78 \%(11)$ & $14,89 \%(07)$ & $21,43 \%(03)$ & $12,88 \%(21)$ \\
\hline - Semiturvo & $79,41 \%(81)$ & $80,85 \%(38)$ & $71,42 \%(10)$ & $79,14 \%(129)$ \\
\hline - Turvo & $9,80 \%(10)$ & $4,25 \%(02)$ & $7,14 \%(01)$ & $7,97 \%(13)$ \\
\hline \multicolumn{5}{|l|}{ Depósito } \\
\hline - Presente & $4,90 \%(05)$ & $8,51 \%(04)$ & $21,42 \%(03)$ & $7,36 \%(12)$ \\
\hline - Ausente & $95,09 \%(97)$ & $91,48 \%(43)$ & $78,57 \%(11)$ & $92,63 \%(151)$ \\
\hline \multicolumn{5}{|l|}{ P.H } \\
\hline - $\quad \mathbf{5 . 0}$ & $0,98 \%(01)$ & $0 \%(00)$ & $7,14 \%(01)$ & $1,23 \%(02)$ \\
\hline - 6.0 & $51,96 \%(53)$ & $61,70 \%(29)$ & $42,86 \%(06)$ & $53,99 \%(88)$ \\
\hline - 6.5 & $45,09 \%(46)$ & $34,04 \%(16)$ & $42,86 \%(06)$ & $41,71 \%(68)$ \\
\hline - $\quad 7.0$ & $1,96 \%(02)$ & $4,25 \%(02)$ & $0 \%(00)$ & $2,45 \%(04)$ \\
\hline $\begin{array}{l}-7.5 \\
\end{array}$ & $0 \%(00)$ & $0 \%(00)$ & $7,14 \%(01)$ & $0,61 \%(01)$ \\
\hline
\end{tabular}

Dentre os valores da análise química destacaram-se os encontrados para proteínas que foram em sua maioria negativos $(60,7 \%)$ e positivos $(1,8 \%)$ sendo indicativo de proteinúria. Para glicose tiveram como resultados negativos $85,9 \%$ e positivos $(2,0 \%)$ para a faixa de 60 a 70 anos. Os resultados para cetonas, bilirrubina, urobilinogênio e hemoglobina apresentaram-se negativos (Tabela 2).

A ação indireta de bactérias conversoras de nitrato em nitrito acarreta na presença deste último nas amostras de urina, onde estão inclusas as enterobactérias, as bactérias não fermentadoras e os cocos Gram positivos. Ao fazer análise dos resultados expostos (tabela 2), observou-se que cinco $(3,1 \%)$ foram positivos e 158 (96,9\%) negativos, contudo a capacidade de conversão não cabe a todas as bactérias, não descartando a possibilidade de infecção urinaria nos casos que o nitrito não se mostrou presente. 
Tabela 2: Distribuição das análises de urina quanto aos parâmetros químicos.

\begin{tabular}{|c|c|c|c|c|}
\hline \multirow{2}{*}{ PARÂMETROS QUÍMICOS } & \multicolumn{3}{|c|}{ FAIXA ETÁRIA (Anos) } & \multirow[t]{2}{*}{$(\mathrm{N}) \%$} \\
\hline & $60-70$ & $71-81$ & $\geq 82$ & \\
\hline $\begin{array}{cl}\text { Proteínas } \\
\qquad & \text { Negativo } \\
\bullet & \text { Traços } \\
\bullet & + \\
\bullet & ++ \\
\bullet & +++\end{array}$ & $\begin{array}{c}57,84 \%(59) \\
30,39 \%(31) \\
5,88 \%(06) \\
3,92 \%(04) \\
1,96 \%(02)\end{array}$ & $\begin{array}{c}74,47 \%(35) \\
12,76 \%(06) \\
4,25 \%(02) \\
8,51 \%(04) \\
0 \%(00)\end{array}$ & $\begin{array}{l}35,71 \%(05) \\
28,57 \%(04) \\
14,29 \%(02) \\
14,29 \%(02) \\
7,142 \%(01)\end{array}$ & $\begin{array}{c}60,74 \%(99) \\
25,15 \%(41) \\
6,13 \%(10) \\
6,13 \%(10) \\
1,84 \%(03)\end{array}$ \\
\hline $\begin{aligned} \text { Glicose } & \\
\bullet & \text { Negativo } \\
\bullet & \mathbf{2 5 0}(+) \\
\bullet & \mathbf{5 0 0}(++) \\
\bullet & \mathbf{1 0 0 0}(+++) \\
\bullet & \mathbf{2 0 0 0}(++++)\end{aligned}$ & $\begin{array}{c}86,27 \%(88) \\
0,98 \%(01) \\
4,90 \%(05) \\
6,86 \%(07) \\
0,98 \%(01)\end{array}$ & $\begin{array}{c}89,36 \%(42) \\
2,13 \%(01) \\
4,25 \%(02) \\
4,25 \%(02) \\
0 \%(00)\end{array}$ & $\begin{array}{c}71,42 \%(10) \\
0 \%(00) \\
7,14 \%(01) \\
21,43 \%(03) \\
0 \%(00)\end{array}$ & $\begin{array}{c}85,89 \%(140) \\
1,226 \%(02) \\
4,91 \%(08) \\
7,361 \%(12) \\
0,613 \%(01)\end{array}$ \\
\hline $\begin{array}{l}\text { Cetonas } \\
\bullet \quad \text { Negativo }\end{array}$ & $100 \%(102)$ & $100 \%(47)$ & $100 \%(14)$ & $100 \%(163)$ \\
\hline $\begin{array}{l}\text { Bilirrubina } \\
\qquad \quad \text { Negativo }\end{array}$ & $100 \%(102)$ & $100 \%(47)$ & $100 \%(14)$ & $100 \%(163)$ \\
\hline $\begin{array}{l}\text { Urobilinogênio } \\
\qquad \quad \text { Negativo }\end{array}$ & $100 \%(102)$ & $100 \%(47)$ & $100 \%(14)$ & $100 \%(163)$ \\
\hline $\begin{array}{l}\text { Hemoglobina } \\
\bullet \quad \text { Negativo }\end{array}$ & $100 \%(102)$ & $100 \%(47)$ & $100 \%(14)$ & $100 \%(163)$ \\
\hline $\begin{array}{cl}\text { Nitrito } & \\
\bullet & \text { Negativo } \\
\bullet & \text { Positivo }\end{array}$ & $\begin{array}{c}97,05 \%(99) \\
2,94 \%(03)\end{array}$ & $\begin{array}{c}97,87 \%(46) \\
2,12 \%(01)\end{array}$ & $\begin{array}{c}92,85 \%(13) \\
7,14 \%(01)\end{array}$ & $\begin{array}{c}96,93 \%(158) \\
3,06 \%(05)\end{array}$ \\
\hline
\end{tabular}

A quantidade de leucócitos e hemácias encontrados nos resultados está evidenciada na tabela 3. Os mesmos foram distribuídos desde valores considerados normais à incontáveis. Conforme tabulação de dados para leucócitos, 151 (92,6\%) encontraram-se com valores de 3 a 5 , sete $(4,3 \%)$ mostraram-se moderados e cinco $(3,1 \%)$ incontáveis.

Para a análise de hemácias foi seguido o mesmo parâmetro dos leucócitos, tendo como distribuição final dos dados obtidos: $154(94,4 \%)$ para a faixa de 3 a 5, cinco $(3,6 \%)$ para moderado e quatro $(2,4 \%)$ para a categoria incontáveis. As hemácias são estimadas em microscopia de urina afim de facilitar o diagnóstico de possíveis lesões do trato urinário.

Por estarem relacionados em alguns casos com processos inflamatórios e infecções, os filamentos de muco e células epiteliais também devem ser mencionados nos resultados de urina. Como mostrado na tabela 3, os filamentos de muco foram distribuídos em raros $(96,9 \%)$, frequentes $(1,2 \%)$ e aumentados $(1,8 \%)$, enquanto as células epiteliais em raras $(96,9 \%)$ e presentes $(3,6 \%)$. A presença dos dois parâmetros foi apresentada mesmo que de forma rara. 
Tabela 3: Distribuição da análise microscópica das urinas quanto aos sedimentos (sedimentoscopia).

\begin{tabular}{|c|c|c|c|c|}
\hline \multirow{2}{*}{$\begin{array}{c}\text { PARÂMETROS DE } \\
\text { MICROSCOPIA DO SEDIMENTO }\end{array}$} & \multicolumn{3}{|c|}{ FAIXA ETÁRIA (Anos) } & \multirow[b]{2}{*}{$\%(\mathrm{~N})$} \\
\hline & $60-70$ & $71-81$ & $\geq 82$ & \\
\hline \multicolumn{5}{|l|}{ Leucócitos } \\
\hline - 3 a 5 & $98,03 \%(100)$ & $89,36 \%(42)$ & $64,28 \%(09)$ & $92,63 \%(151)$ \\
\hline - Moderado & $0 \%(00)$ & $8,51 \%(04)$ & $21,42 \%(03)$ & $4,30 \%(7)$ \\
\hline - Incontáveis & $1,96 \%(02)$ & $2,12 \%(01)$ & $14,28 \%(02)$ & $3,06 \%(5)$ \\
\hline \multicolumn{5}{|l|}{ Hemácias } \\
\hline - $\quad 3$ a 5 & $96,07 \%(98)$ & $93,61 \%(44)$ & $85,71 \%(12)$ & $94,48 \%(154)$ \\
\hline - Moderado & $1,96 \%(02)$ & $4,25 \%(02)$ & $7,14 \%(01)$ & $3,6 \%(5)$ \\
\hline - Incontáveis & $1,96 \%(02)$ & $2,12 \%(01)$ & $7,14 \%(01)$ & $2,45 \%(4)$ \\
\hline \multicolumn{5}{|l|}{ Filamento de muco } \\
\hline - $\quad$ Raro & $97,05 \%(99)$ & $97,87 \%(46)$ & $92,85 \%(13)$ & $96,93 \%(158)$ \\
\hline - Frequente & $0,98 \%(01)$ & $2,12 \%(01)$ & $0 \%(00)$ & $1,23 \%(2)$ \\
\hline - Aumentado & $1,96 \%(02)$ & $0 \%(00)$ & $7,14 \%(01)$ & $1,84 \%(3)$ \\
\hline \multicolumn{5}{|l|}{ Células epiteliais } \\
\hline - Raro & $97,05 \%(99)$ & $97,87 \%(46)$ & $92,85 \%(13)$ & $96,93 \%(158)$ \\
\hline - $\quad$ Presente & $2,94 \%(03)$ & $2,12 \%(01)$ & $7,14 \%(01)$ & $3,6 \%(5)$ \\
\hline \multicolumn{5}{|l|}{ Cilindros } \\
\hline - Ausente & $97,05 \%(99)$ & $97,87 \%(46)$ & $92,85 \%(13)$ & $96,93 \%(158)$ \\
\hline - Presente & $2,94 \%(03)$ & $2,12 \%(01)$ & $7,14 \%(01)$ & $3,96 \%(05)$ \\
\hline \multicolumn{5}{|l|}{ Flora bacteriana } \\
\hline - Discreta & $97,05 \%(99)$ & $97,87 \%(46)$ & $92,85 \%(13)$ & $96,93 \%(158)$ \\
\hline - Moderada & $1,96 \%(02)$ & $0 \%(00)$ & $7,14 \%(01)$ & $1,84 \%(03)$ \\
\hline - Aumentada & $0,98 \%(01)$ & $2,12 \%(01)$ & $0 \%(00)$ & $1,22 \% \quad(02)$ \\
\hline \multicolumn{5}{|l|}{ Cristais } \\
\hline - Ausente & $78,43 \%(80)$ & $64,95 \%(31)$ & $71,42 \%(10)$ & $74,23 \%(121)$ \\
\hline - $\quad$ Ácido úrico & $6,86 \%(7)$ & $8,51 \%(4)$ & $7,14 \%(01)$ & $7,36 \%(12)$ \\
\hline - Fosfato triplo & $4,90 \%(5)$ & $10,63(5)$ & $7,14 \%(01)$ & $6,74 \%(11)$ \\
\hline - Oxalato de cálcio & $7,48 \%(8)$ & $12,76 \%(6)$ & $7,14 \%(01)$ & $9,20 \%(15)$ \\
\hline - Urato amorfo & $1,96 \%(2)$ & $2,12 \%(1)$ & $7,14 \%(01)$ & $2,45 \%(4)$ \\
\hline
\end{tabular}

Ao fazer a relação dos dados de acordo com as faixas etárias estipuladas, foi possível inferir que não houveram diferenças quanto a variável predominante, uma vez que os resultados se mostraram semelhantes. Logo, é necessário dar importância para variáveis com menor frequência, pois entende-se que uma pequena porção a curto prazo, pode estar vinculada a uma grande quantidade de idosos ao decorrer do ano.

\section{Discussão}

Os fatores de risco para desenvolvimento de ITU em homens estão relacionados com a instrumentação das vias urinárias e hiperplasia prostática. O que caracteriza a infecção como hospitalar se dá pelo fato de microrganismos serem introduzidos por meio de alguma instrumentação - como cateterismo vesical - e uma vez que a bexiga não é esvaziada totalmente, favorece a proliferação até que atinja altos índices de concentração (MARANGONI, 1994).

As taxas de ITU são elevadas não apenas pelos fatores citados, mas também pela presença de patologias associadas em idosos e em pacientes hospitalizados. Em homossexuais masculinos, as taxas de infecção são mais elevadas devido ao ato sexual anal desprotegido, o que facilita a entrada de microrganismos fecais pela uretra, em indivíduos com prepúcio íntegro e em pacientes infectados pelo HIV (RORIZ-FILHO, 2010).

Utilizado como método diagnóstico complementar desde o século II, o exame de urina tipo I pode fornecer sinais importantes sobre patologias, principalmente doenças renais e nas vias urinárias. A existência de sangue, leucócitos, proteínas e diversos outros achados sugerem a presença de distúrbios que podem ainda não ter sido diagnosticados. (CARVALHAL, 2006). 


\section{Biomedica Brasiliensia}

Segundo Lopes (2004) e Da Cruz et. al (2005), a coloração amarela da urina se deve ao resultado da excreção de três pigmentos, urocromo (amarelo), uroeritrina (vermelho) e urobilina (laranja) que são gerados no metabolismo natural do organismo. A acentuação da cor da urina está associada com a concentração da amostra que se altera por conta de vários fatores, tais como alimentos ingeridos, realização de atividades físicas, medicamentos, nível de hidratação, entre outros, com isto faz-se necessário que o ambiente onde o material será analisado disponha de boa iluminação. Assim uma urina mais clara ou mais escura irá corresponder à um aumento ou escassez no consumo de líquidos, respectivamente. Uma parcela dos dados encontrados se apresentou em coloração amarelo âmbar (13,50\%), sendo referentes a indivíduos com baixa ingesta de líquidos (ROCHA, 2014).

A transparência da urina é referenciada pelo termo aspecto, usualmente descrito como límpido, semiturvo e turvo. Logo após sua emissão, a urina normal apresenta-se clara e transparente, no entanto quando ocorre precipitação de alguns cristais amorfos (fosfatos e uratos), sua aparência altera e ela tende a ficar turva (DA CRUZ, 2005). A relação entre aspecto e depósito juntamente com a quantidade de estruturas visualizadas na microscopia é imensamente estreita, uma vez que a alteração do aspecto da amostra se dá por conta de estruturas suspensas que se depositam após o repouso ou centrifugação. Neste estudo foi possível observar que dos 163 idosos, $13(7,97 \%)$ se mostraram com turvação e destes, 12 (7,36\%) apresentaram depósitos, corroborando assim, com os dados encontrados.

Para identificar previamente infecções bacterianas no trato urinário, é realizada a investigação de nitrito na urina, visto que a presença de bactérias gram-negativas na amostra analisada converte o nitrato em nitrito (LOPES 2004). Vale ressaltar que o nitrito ingerido em medicamentos ou alimentação não é eliminado na amostra e que outras bactérias patogênicas não produtoras de enzimas que reduzem nitrato podem estar presentes, assim também causando infecção (STRASINGER, 2008). No estudo foi observado que $158(96,9 \%)$ resultados se mostraram negativos quanto a presença de nitrito enquanto $5(3,1 \%)$ foram positivos, sendo estes sugestivos de infecção.

Um achado comum no exame de urina para sugestão de ITU é o de leucócitos, embora não estando relacionado com uma infecção, ele pode estar presente em diversas situações, como lesão, irritação ou qualquer inflamação que não esteja associada a um agente nocivo, contudo, algumas alterações inflamatórias do trato urinário possibilita a presença de leucócitos na amostra sem que exista infecção ativa, como por exemplo litíase urinária. Dentre os achados, leucocitúria é o mais sugestivo para ITU conforme seja constatado um número elevado de leucócitos por campo, pois para ser considerado normal os valores variam em torno de 3 a 5 (CARVALHAL, 2006 e STRASINGER, 2008). Nossos resultados demonstraram a predominância de níveis normais (92,63\%), no entanto, o fato do número de resultados de exames positivos (12) ter sido relativamente baixo, se comparado com a quantidade total de amostras, não descarta a importância para os achados de leucócitos no exame de urina tipo 1, pois qualquer evidência já se torna um alerta para existência de infecção.

As hemácias não conseguem adentrar no filtrado glomerular íntegro, de forma que ao ser encontrada mais de uma célula por campo, pode corresponder a alguma anormalidade. A presença das mesmas na urina (Hematúria) está relacionada com lesões na membrana dos glomérulos ou nos vasos do sistema urogenital (DA CRUZ, 2005). Na microscopia, a existência de hemácias na amostra pode estar relacionada com piúria ou bacteriúria, em compensação na macroscopia ela raramente está associada com ITU. (MARANGONI, 1994). Dentre os resultados encontrados, o número de hemácias de 3 a 5 se mostrou mais prevalente, equivalendo a $154(94,4 \%)$ e assim como os leucócitos, os nove casos que elas se mostraram em maior quantidade não devem ser subestimados.

Os diversos tipos de células epiteliais, classificados de acordo com sua localização, são encontrados no sedimento por conta da descamação habitual de células velhas que revestem o 
epitélio do trato geniturinário. Processos inflamatórios ou doenças renais podem estar relacionados com a presença de algumas células epiteliais eliminadas na urina, como por exemplo, células dos túbulos renais que ao serem encontradas em grande quantidade, indicam necrose tubular (LOPES, 2004 e DA CRUZ 2005). É importante lembrar que os dados analisados não diferem os tipos de células encontradas quanto a sua localização, dessa forma foram apresentados em cinco $(3,6 \%)$ pacientes a presença deste achado, evidenciando suposta infecção.

\section{Conclusão}

Os resultados apontados por esta pesquisa demonstraram que a saúde do homem, mais especificamente a saúde do homem idoso passa por descuido recorrente, visto que muitas patologias, por mais que em pequena proporção, atingem uma parcela da população que foi objeto alvo do estudo. Alguns parâmetros como cor, densidade e depósitos apresentam íntima relação, que por serem de característica macroscópica, tornam sua manutenção mais viável por meio de boa hidratação e alimentação saudável. Conscientizar os profissionais da saúde e orientar os pacientes quanto a esses cuidados e em fazer o exame de urina tipo I rotineiramente é de suma importância.

É importante ficar atento a prevalência de ITU, ao possível grau de suscetibilidade que pode ser apresentado e que mais estudos sejam realizados na área para que se tenha um controle mais específico de qual faixa etária é a mais acometida.

\section{Referências}

ANDREOLI, T. E.; BENNETT, J. C.; CARPENTER, C. C. J.; PLUM, F. Cecil Medicina interna básica. 4 ed. Rio de Janeiro: Guanabara - Koogan, 1997. p. 171 -241.

Associação Medica Brasileira - Conselho Federal de Medicina - Projeto Diretrizes Infecções do Trato Urinário: Diagnostico. Sociedade Brasileira de Infectologia e Sociedade Brasileira de Urologia, 2004. [Internet] Disponível em: //www.projetodiretrizes.org.br/projeto_diretrizes/067.pdf>. Acesso em: 06/10/2016

CARVALHAL, G. F.; ROCHA, L. C. A.; MONTI, P. R. Urocultura e exame comum de urina: considerações sobre sua coleta e interpretação. Revista da AMRIGS, v. 50, n. 1, p. 59-62, 2006.

DA CRUZ, C. S. O.; BERGAMASCHI, G. C. Desenvolvimento e utilização de conservante químico em amostras de urina para análises microbiológicas (urocultura) e rotina (EAS). RBAC, v. 37, n. 3, p. 137-147, 2005.

DUARTE, G. et al. Urinary tract infection in pregnancy. Revista Brasileira de Ginecologia e Obstetrícia, v. 30, n. 2, p. 93-100, 2008.

LOBATO, O. Elaboração diagnóstica em nefrologia. Revista CASL, 27:7 1 - 90, 1965.

LOPES, H.V; TAVARES, W. Projeto Diretrizes - Associação Médica Brasileira (AMB) e Conselho Federal de Medicina (CFM); Sociedade Brasileira de Infectologia e Sociedade Brasileira de Urologia. Infecções do Trato Urinário: Diagnóstico, 2004.

LOPES, H. J. J. O laboratório clínico na avaliação da função renal. Belo Horizonte: Gold Analisa Diagnóstico Ltda, p. 27, 2004. 
MARANGONI, D. V.; MOREIRA, B. M. Infecções do Trato Urinário. In: Mauro Schechter; Denise Vantil Marangoni. (Org.). Doenças Infecciosas: Conduta Diagnóstica e Terapêutica. 1ed. Rio de Janeiro, RJ Brasil: Guanabara Koogan, 1994, p. 302-324

MASSON, P. et al. Meta-analyses in prevention and treatment of urinary tract infections. Infectious disease clinics of North America, v. 23, n. 2, p. 355-385, 2009.

NETO, O. M. V. Infecção do trato urinário. Medicina (Ribeirão Preto. Online), v. 36, n. 2/4, p. 365-369, 2003.

ROCHA, A. Biodiagnósticos - Fundamentos e técnicas laboratoriais. 1 ed., São Paulo, Editora Riedeel, 2014.

RORIZ-FILHO, J. S. et al. Infecção do trato urinário. Medicina (Ribeirão Preto. Online), v. 43, n. 2, p. 118-125, 2010.

SANTOS, S. R.; AMADO, C.A.B.; ASSEF, S.M.C. Infecções urinárias. Arq Ciênc Saúde Unipar, v. 3, n. 1, p. 43-50, 1999.

SILVA, J. M. P. et al. Aspectos atuais no diagnóstico e abordagem da infecção do trato urinário. p. 20-30, 2014.

STRASINGER, S. K.; DI LORENZO, M. S. Urinalysis \& Body Fluids. FA Davis, 2008.

ZAMAN, A.B. Disappointing dipstick screening for urinary tract infection in hospital in patients. J Clin Pathol, v. 51, p. 471-2, 1998. 